\title{
Páginas censuradas: la literatura brasileña en los años 70
}

Helena Bonito Couto Pereira

hbcpereira@mackenzie.br Universidad Presbiteriana Mackenzie

Resumen: La censura se intensificó en Brasil particularmente entre 1969 y 1978, periodo de vigencia del AI-5. Mientras la prensa era sometida a censura previa, los libros eran alcanzados por la censura con base en denuncias y podían ser condenados, por la sindicación de rótulos como «subversivos» o «contra la moral y las buenas costumbres». Después de la condena, podían ser vetados para comercialización, tomados o destruidos. La ausencia de criterios por parte de los censuradores trajo intranquilidad, desorientación y hasta autocensura por parte de los escritores. No faltó, sin embargo, quien se expusiese, empleando expresiones transgresoras, trayendo a flote la violencia y el deterioro de las relaciones humanas y sociales. Una manera de perfilar el problema, conforme ya observaron historiadores y críticos, consistió en la creación de narradores irónicos, responsables por textos satíricos o alegóricos. Entre ellos destaca Zero, de Ignacio de Loyola Brandão, o «Rebelião dos mortos» (La rebelión de los muertos), premiado cuento de Luiz Fernando Emediato. El énfasis ideológico presente en esas narraciones atrajo las denuncias que resultaron, de hecho, en su prohibición. Por otro lado, la publicación de Incidente em Antares (1973, Incidente en Antares), de Érico Veríssimo, demuestra que la narrativa alegórica podía alcanzar al gran público sin sufrir ninguna cercenadura

a por parte de la censura, posiblemente gracias al renombre del autor. Teniendo en cuenta que en tales obras sobresalen componentes temáticos relacionados a denuncia o contestación, el presente estudio discute los recursos estilísticos que los escritores utilizaron para distanciarse de la capa denotativa y del mero realismo descriptivo o panfletario, ampliando considerablemente el abanico de lecturas para esos textos.

Palabras clave: literatura brasileña, censura, Ignacio de Loyola Brandão, Érico Veríssimo.

Abstract: Censorship growth in Brazil specially between 1969 and 1978, during AI-5 validity. Meanwhile periodic press was submitted to previous censorship, books used to be hired by censors based on denounces and would be condemned by pressing on cover advertising words as «subversives» or "dangerous to moral». After condemned, they could be forbidden to commerce, seized or destroyed. The absence of standards by censors brought some agitation, misguides and 
even self-censorship by authors. It did not miss, however, those who expose themselves, by using forbidden expressions, bringing issue violence and loss of human and social relationships. A manner to surpass this problem, as observed by critical and historians is creation of ironic narrators, responsible by satiric or allegoric texts. Among those, we can light Zero, from Ignacio de Loyola Brandão, or «Rebelião dos mortos», awarded short story written by Luiz Fernando Emediato. The ideological emphasis shown by those narratives shall fatally attract denounces that results, in fact, in its prohibition. On other hand, printing of Erico Verissimo's Incidente em Antares (1973), shows that allegoric narrative could access mainstream suffering no punishment by censorship, possibly because author's fame. Considering that in this kind of books stand out thematics components, which are related to denounce and contestation, this article discuss stylistic resources used by writers to get distance of denotative layer and mere descriptive realism, enlarging the row of lectures to those texts.

Keywords: Brazilian literature, censorship, Ignacio de Loyola Brandão, Érico Veríssimo

$\mathrm{E}$ período que permanece en nuestro imaginario como «década del 70» corresponde al auge del llamado Milagro Brasileño, marcado por la euforia de una clase media que finalmente conseguía el acceso a bienes de consumo como el automóvil popular cero quilómetros y la televisión a colores, aun en la feliz ignorancia en cuanto a los intereses que - literalmente- le serían cobrados en las décadas siguientes, por cuenta de los recursos que venían profusamente, de las metrópolis capitalistas donde había exceso de liquidez, conforme señala Gaspari (2002: 472). En amplios sectores de la sociedad brasileña de la época, la seudoentrada en el maravilloso mundo del consumo camuflaba las voces que se contraponían a la truculencia y a las arbitrariedades del gobierno militar. En el imaginario cultural, el periodo estuvo marcado, desde el inicio, por un aura de transgresión, traída por los jóvenes bahianos con la Tropicalia, entre otros movimientos. Estuvo marcada también por la resistencia de la prensa, silenciada a la fuerza por la censura, o por las acciones violentas que destruían puestos donde hubiese a la venta periódicos prohibidos. Estuvo marcada incluso por la resistencia que se ejerció en ambientes culturales como el cine y el teatro. En este último, agresión y prisión podían alcanzar inclusive actores al final del espectáculo, como ocurrió con el elenco de Roda viva, de Chico Buarque, en 1968.

La censura manifiesta se institucionalizó, explicitando su condición de mecanismo auxiliar de represión. Cuando se lanza una mirada ligera a las publicaciones literarias censuradas en la década del 70, se puede tener la impresión de que la censura tomó por blanco a la literatura de modo similar a lo que hacía con la prensa, el teatro y el cine. Finalmente, fueron prohibidas obras como Feliz ano novo, de Rubem Fonseca, o Zero, 
de Ignácio de Loyola Brandão. Una mirada más atenta, todavía, revela que publicaciones literarias stricto sensu, como la poesía y la narrativa de ficción, que se vuelven necesariamente para un público especializado y en número reducidísimo al conjunto de la clase media para no decir de la población- brasileña, no sufrieron, por parte de la censura, la vigilancia implacable que se abatió contra otros sectores de la producción cultural. Curiosamente, cuando focalizamos el campo literario, descubrimos que la censura se mostró poco actuante o prácticamente omisa. Ni siquiera con la promulgación del AI-5, en diciembre de 1968, las obras literarias pasaron a ser examinadas más atentamente por los censores.

Durante algunos ańos, mientras que la prensa era sometida a censura previa, con los desordenes y las arbitrariedades bien conocidos, la publicación y circulación de libros se realizaban al gusto del mercado. Se editaban anualmente casi 10000 títulos, que, en su mayoría, no tenían relación alguna con literatura. Si el gran público nunca llegara a completar un número expresivo de lectores, ese cuadro no se volvería mejor al inicio de los ańos 70, cuando se consolidó el consumo de masas de bienes de todo tipo, inclusive culturales.

Sin llegar al gran público, la literatura pasó más o menos incólume durante algunos años. En «Censura: uma pista dupla» (Censura: una pista doble), Flora Süssekind observa que, aunque la censura a las obras literarias fuese esporádica, su espectro sobrevolaba, inquietante, como una amenaza a los escritores:

Ese es el periodo en que más claramente se pasa a sentir la presencia de un censor al lado de la máquina de escribir. Una especie de Fleury de las letras acompaña de cerca la producción literaria de los años 70. «En vez de dialogar con la realidad, nuestra interlocutora predilecta era la censura. Así, la realidad se fue convirtiendo en un espejismo, y la censura fue perdiendo su tradicional papel policial y burocrático para convertirse en musa inspiradora», comentó Geraldo Carneiro en un artículo publicado en la «Revista de Domingo» del Jornal do Brasil en 7 de abril de 1985. (2004: 31)

1 «Esse é o período em que mais claramente se passa a sentir a presença de um censor ao lado da máquina de escrever. Uma espécie de Fleury das letras acompanha de perto a produção literária dos anos 70. 'Em vez de dialogar com a realidade, nossa interlocutora predileta era a censura. Assim, a realidade foi se convertendo em miragem, e a censura foi perdendo o seu tradicional papel policial e burocrático para se converter em musa inspiradora', comentou Geraldo Carneiro em artigo publicado na «Revista de Domingo» do Jornal do Brasil em 7 de abril de 1985». (2004: 31) 


\section{HELENA BONITO COUTO PEREIRA}

La imprevisibilidad de la actuación de los censores en relación a las narrativas literarias acarreó intranquilidad, desorientación y ese sorprendente desvío o «Fleury de las letras», alusión al policial que personificaba la cara más cruel y tenebrosa de la represión. Así, los escritores interiorizaban involuntariamente una autocensura cuyos resultados aparecerían más tarde, cuando, después de la apertura política, sectores de la intelectualidad esperaban por una verdadera cosecha de obras primas que nunca se concretizó.

Para tomar como blanco determinada obra, los censores dependían de denuncias que llegaban hasta ellos espontáneamente, venidas de lectores conservadores y de autoridades celosas en relación «a la moral y a las buenas costumbres», o preocupadas por «mantener el orden institucional». Al condenar determinado libro, la censura podía impedir su edición, recoger la distribución eventualmente efectuada o igualmente mandar a tomar y destruir todos los ejemplares producidos. En la práctica, esos procedimientos fueron responsables por la acción preventiva de los escritores que, además de someterse a un «Fleury» imaginario, se ponían a «dialogar con la censura» antes de ser alcanzados por ella. Aunque de acuerdo con Süssekind,

No se trata, sin embargo, de ignorar la importancia de la censura o del aparato represivo que, hasta cuando no era puesto en acción, se sabía que estaba listo para cualquier eventualidad. Como, por ejemplo retirar de circulación, algún tiempo después de lanzado, un libro como Feliz ano novo [Feliz ańo nuevo], de Rubem Fonseca, en diciembre de 1976, o, no limitándose solo a prohibir la obra, detener a su autor, como se hizo con Renato Tapajós durante un mes en 1977, después de aprehendido el romance Em câmara lenta [En cámara lenta]. O, incluso, como la prohibición pura y simple de libros como Zero, de Ignacio de Loyola Brandão, lanzado en Brasil en 1975, y retirado de circulación al año siguientes, o como A rebeliáo dos mortos [La rebelión de los muertos], de Luiz Fernando Emediato, premiado en 1977 y prohibido en 1978. (2004: 44)

2 «Não se trata, no entanto, de ignorar a importância da censura ou do aparato repressivo que, mesmo quando não era acionado, sabia-se que estava a postos para qualquer eventualidade. Como, por exemplo retirar de circulação, algum tempo depois de lançado, um livro como o Feliz ano novo, de Rubem Fonseca, em dezembro de 1976, ou, não se limitando apenas a proibir a obra, prender seu autor, como se fez com Renato Tapajós durante um mês em 1977, depois de apreendido o romance Em câmara lenta. Ou, ainda, como a proibição pura e simples de livros como Zero, de Ignacio de Loyola Brandão, lançado no Brasil em 1975, e retirado de circulação no ano seguinte, ou como A rebelião dos mortos, de Luiz Fernando Emediato, premiado em 1977 e proibido em 1978». (2004: 44) 
De las peripecias por las que pasaron algunas de esas narrativas, más precisamente Zero y $A$ rebeliáo dos mortos (La rebelión de los muertos), surgió la motivación para el presente trabajo. Si fuese verdadera la impresión de que la censura había sido ejercida ferozmente contra la prosa de ficción durante todo el periodo militar, la condena no habría quedado a un pequeño conjunto de cuentos y romances que habían alcanzado visibilidad mediática. Habría alcanzado narrativas que presenten componentes ideológicos similares, como Incidente em Antares, de Érico Veríssimo, lanzado en 1971, o As meninas, de Lygia Fagundes Telles, publicado dos años después. Expresiva parcela de la producción ficcional del periodo presenta la alegoría como recurso para elaborar sus representaciones de la realidad brasileña.

\section{Narrativa brasileña pos 1964}

ilviano Santiago caracteriza la narrativa brasileña de los años 70 a partir de los vínculos
con su antecesor por excelencia, el regionalismo, cuyos temas dominantes focalizaban la exploración del hombre por el hombre. Al abandonar gradualmente esa temática, la ficción encuentra, a decir del crítico, «su propia originalidad»:

Estilísticamente, la literatura brasileña pos 64 puede, por un lado, retomar una lección del pasado, ajustándose [...] a principios estéticos fundamentados por el realismo de los años 30. Puede también, por otro lado, aproximarse a la literatura hispanoamericana $[\ldots]$. En este segundo caso, se adentra al texto literario por una escritura metafórica o fantástica, hasta entonces prácticamente inédita entre nosotros. $(2002: 14)^{3}$

Buena parte de los teóricos que se ocuparon de ese periodo señalan el predominio de dos tipos de narrativa: una que recupera, de diferentes maneras, el realismo regionalista, y otra que adopta la escritura alegórica o fantástica. Aunque a decir de Santiago,

3 «Estilisticamente, a literatura brasileira pós-64 pôde, por um lado, retomar uma lição do passado, ajustando-se [...] a princípios estéticos fundamentados pelo realismo dos anos 30. Pôde também, por outro lado, aproximarse da literatura hispano-americana [...]. Neste segundo caso, adentra-se o texto literário por uma escrita metafórica ou fantástica, até então praticamente inédita entre nós». (2002: 14) 


\section{HELENA BONITO COUTO PEREIRA}

Hubo una primera y camuflada respuesta de la literatura a las imposiciones de censura y represión hechas por el régimen militar: la prosa de intriga fantástica y estilo onírico en que el intrincado juego de metáforas y símbolos transmitía una crítica radical de las estructuras de poder en el Brasil [...]. Hubo además el romance-reportaje [...], en que se denunciaban los arbitrios de la violencia militar y policial en los años duros del AI-5, arbitrios estos que han sido escondidos de la población en virtud de la censura impuesta a las redacciones de periódicos y a los estudios de televisión. $(2002: 17)^{4}$

No hay consenso, entre los críticos, en cuanto a una dicotomía tan nítida como la anotada arriba, ni en cuanto a su principal intención de camuflarse ante la censura. En «Jornal, realismo, alegoria: o romance brasileiro recente» («Periodismo, realismo, alegoría: el romance brasileño reciente») Davi Arrigucci considera que hay en la literatura de los años

Un deseo muy fuerte de volver a la literatura mimética, de hacer una literatura cercana al realismo [...] y con un lastre muy fuerte de documento. Por tanto, dentro de la tradición del romance brasileño, desde los orígenes. Eso se colocó a través de una especia de neonaturalismo, de neo-realismo que [...] está ligado a las formas de representación del periódico. (1999: 77) $)^{5}$

Vinculados a ese modo de representar, según Arrigucci, se encuentran tres niveles: el que adopta la técnica del romance-reportaje, como Lúcio Flávio, de José Louzeiro, otro que «se construye sobre la imitación de técnicas del periodismo, sobre todo del montaje», como en Reflexos do baile (Reflejos del baile), de Antônio Callado, y un tercero, que pretende representar determinado segmento de la realidad, como Cabeça de papel (Cabezas de papel), de Paulo Francis. Arrigucci finaliza la ejemplificación afirmando que se trata de «tres casos

4 «Houve uma primeira e camuflada resposta da literatura às imposições de censura e repressão feitas pelo regime militar: a prosa de intriga fantástica e estilo onírico em que o intrincado jogo de metáforas e símbolos transmitia uma crítica radical das estruturas de poder no Brasil [...]. Houve ainda o romance-reportagem [...], em que se denunciavam os arbítrios da violência militar e policial nos anos duros do AI-5, arbítrios estes que tinham sido escondidos da população em virtude da censura imposta às redações de jornal e aos estúdios de televisão».

5 «...um desejo muito forte de voltar à literatura mimética, de fazer uma literatura próxima do realismo [...] e com um lastro muito forte de documento. Portanto, dentro da tradição do romance brasileiro, desde as origens. Isso se colocou através de uma espécie de neonaturalismo, de neo-realismo que [...] está ligado às formas de representação do jornal». 
de alegoría, ligados con la voluntad realista de representar lo que fue, lo que ha sido la realidad, la voluntad de mantener la verosimilitud y usando siempre la alegoría» (1999: 78). Más adelante, el mismo crítico agrega que las condiciones sociales favorecen «una alegoría generalizada», que se instaura en conflicto con un impulso realista que permanece: «En el impulso realista, el procedimiento alegórico es problemático. Si yo construyo de acuerdo con la ficción realista, yo tengo dificultades para tratar de forma alegórica» (1999: 91 y 94) Esas afirmaciones, resultantes de un debate y publicado en 1979, fueron objeto de innumerables citaciones en textos críticos posteriores, entre otras razones porque hacen referencia a la representación de la alegoría de la modernidad, formulada por Walter Benjamin y discutida por Luckács.

La vinculación entre alegoría y circunstancias políticas tienen diversas implicaciones. Como consecuencia de la censura impuesta a la prensa periódica, Flora Süssekind considera que la literatura asumió para sí una misión "paraperiodística», con dos tipos de solución: las respuestas directas, correspondientes a un naturalismo reditado, y las indirectas, concretizadas en parábolas (2004: 17). Ambas denotan un problema que pocas veces ha sido percibido:

Raramente se pregunta, por ejemplo, por qué la preferencia por estas dos faces del realismo (mágico o periodístico), por una literatura sobrepoblada de pistas alegóricas y obcecada por la referencialidad, y no por un lenguaje menos «figurado» y más ficcional, más seca, y cuyas elipses podrían responder de modo tal vez más crítico a los silencios impuestos por el régimen autoritario [...] Cabría preguntar, en suma, ¿por qué la victoria de las parábolas, biografías y del naturalismo en detrimento de una literatura que jugase más con la elipse y el chiste? En general siquiera se piensa en la posibilidad de un encaminamiento menos documental o alegórico para la literatura del periodo. Imaginase que esas serían las únicas salidas posibles teniendo en vista el rigor de la censura. $(2004: 18-20)^{6}$

6 «Raramente se pergunta, por exemplo, por que a preferência por estas duas faces do realismo (mágico ou jornalístico), por uma literatura superpovoada de pistas alegóricas e obcecada pela referencialidade, e não por uma linguagem menos 'figurada' e mais ficcional, mais seca, e cujas elipses poderiam responder de modo talvez mais crítico aos silêncios impostos pelo regime autoritário. [...] Caberia perguntar, em suma, por que a vitória das parábolas, biografias e do naturalismo em detrimento de uma literatura que jogasse mais com a elipse e o chiste? Em geral sequer se pensa na possibilidade de um encaminhamento menos documental ou alegórico para a literatura do período. Imagina-se que essas seriam as únicas saídas possíveis tendo em vista o rigor da censura ». 
$\mathrm{Al}$ identificar entre las marcas de la ficción del periodo, el papel secundario de la elaboración textual, Süssekind hace una cobranza extemporánea y deja a cargo de otros investigadores la tarea de buscar, en las entrelíneas del texto realista o alegórico, el deseable encaminamiento «menos documental o menos alegórico».

En Itinerário político do romance pós-64: A festa (Itinerario político del romance pos 64: la fiesta), Renato Franco también reconoce la fuerte presencia de la alegoría, que "parece haber sido un de los conceptos-clave empleados por la crítica más empeñada en interpretar el romance de la década del 70» (1998: 144), pero no concuerda con la identificación entre alegoría y censura. De acuerdo con Arrigucci, quien también retoma el problema de la representación alegórica según Benjamin, afirma que la alegoría surge en la modernidad como consecuencia «de la muerte del sujeto clásico, aliada al proceso irreversible de desintegración de los objetos», lo que repercutió intensamente en el romance contemporáneo, que, «consciente de su inserción en ese torbellino de incesantes transformaciones, se desnuda: desmascara sus pretensiones, expone sus procedimientos y su arquitectura» (1998: 148).

De esa forma, el retorno de la representación alegórica ultrapasa un impulso de fuga, circunstancial, hace a la censura, lo que lo lleva a refutar directamente las afirmaciones de Süssekind. Para esta última, las alegorías de las narrativas de ese periodo se construyen en bases denotativas, sobre simplificaciones, y así permiten un rápido pasaje del caso particular a la totalidad. En otras palabras, las alegorías impiden la pluralidad y aniquilan la polisemia del texto literario: «La misma llave maestra político-referencial abre todas las puertas» (2004: 102-103).

Franco apunta como gran equivocación de la sugerencia de Süssekind que el recurso a la alegoría habría sido adoptado en los romances de los años 70 «para driblear los impedimentos de la censura y establecer con los lectores una especie de pacto significativo [...] para captar, por detrás del velo de la interdicción, la reluciente realidad de los hechos veríditas» (1998: 146). Para finalizar, Franco ve en las afirmaciones de Süssekind en cuanto a la ausencia de otros encaminamientos menos documentales o alegóricos en la prosa la defensa de una concepción de romance que se aleja tanto de la sustancia histórica como de la vida política; un romance, en fin, dirigido para el trabajo artístico con el lenguaje.

Sin la pretensión de colocar un punto final en la discusión, nos parece relevante discutir, en los límites de este estudio, como la alegoría se presenta en tres narrativas ficcionales, de las cuales dos fueron prohibidas por la censura y una pudo circular libremente 
en todo el territorio nacional. En el primer caso se encuentra «A rebelião dos mortos» (La rebelión de los muertos), de Luiz Fernando Emediato e Zero (Cero), de Ignacio de Loyola Brandão, y en el segundo Incidente em Antares (Incidente en Anteres), de Érico Veríssimo.

\section{"A rebelião dos mortos»}

【as peripecias que cercan la creación y la publicación de ese cuento de Luiz Fernando entre 1974 y 1978, en ese periodo Emediato obtiene increíbles 25 premiaciones literarias. Poco publicó después, habiéndose vuelto para la actividad periodística, como informa Luiz Ruffato en el prefacio al recién publicado Trevas no paraíso (Tinieblas en el paraíso) (2004: 14) compilación de cuentos con el sugestivo subtítulo de "Histórias de amor e morte nos anos de chumbo» (Historias de amor y muerte en los años de plomo).

En su primera edición, $A$ rebelião dos mortos (La rebelión de los muertos) se compone de nueve cuentos. El cuento que presta el título al libro es significativo, no solo del punto de vista literario propiamente dicho, ilustra, involuntariamente, las vicisitudes de la producción literaria en el periodo. En 1977, «A rebelião dos mortos» (La rebelión de los muertos) ganó el Concurso de Literatura Ciudad de Belo Horizonte, pero, después del anuncio de la premiación, la prefectura municipal rechazó editar el libro, conforme estaba previsto en el reglamento del concurso, y no pagó el premio estipulado. Después de ese episodio, la comisión organizadora del referido concurso pasó a contar con un censor y Emediato emprendió una lucha sin gloria, durante años, para finalmente obtener el premio y la publicación.

Completamente alegórico, el cuento se inicia por una noticia que podría pasar por objetiva, enunciada por un narrador supuestamente neutro: «La rebelión de los muertos comenzó en la sombría mañana de 1. ${ }^{\circ}$ de abril de 1964.» (Emediato 2004: 138). Se organiza la Gran Marcha para Brasilia, compuesta exclusivamente por muertos, descritos como "gente sin rostro, sin color y sin brazos, que viviera en blanco por millares de existencias» (2004: 139). Ese relato es substituido por otro, de un «escritor famoso», que «engalanó el torpe ejército de armas y medallas y enumeró entre sus líderes todos los fantasmas de la Historia Nacional» (2004: 39). La versión de este segundo narrador (indirecto) vendió centenas de millares de ejemplares. Mientras tanto, el escritor famoso es encontrado muerto, y en su mano izquierda hay un billete que revela su intención de "esclarecer todo». A pesar de la 


\section{HELENA BONITO COUTO PEREIRA}

rápida intervención de la policía, «un periodista joven, delgado, rubio y rebelde» escribe un artículo sobre las posibles imprecisiones históricas sobre la Gran Marcha, volviéndose el tercer narrador (también indirecto). Su artículo contradice el libro del segundo narrador:

El líder del macabro Ejército revoltoso no sería el Alferes Tiradentes, como garantía la obra de nuestro difunto autor, pero sí un operario de la industria siderúrgica llamado Osman u Osmar. Su lugarteniente no sería, de la misma forma, el fantasma hercúleo, sin embargo impotente, del intrépido Araribóia [...] Era tan solamente el artesano negro Benedito Airão. $(2004: 140)^{7}$

Se ordena rápidamente la aprehensión de ese artículo, en cuanto otro periódico lanza una edición especial con reportaje sobre el «inolvidable autor de La gran marcha». La voz narrativa vuelve a ese autor, con la transcripción de un enorme fragmento de su obra, en que se reafirma el relato anterior, aumentado de innumerables detalles.

La gran marcha seguía heroicamente por el Rio Brasilia, teniendo al frente, como líder mayor e indiscutible, el alto y delgado, y solerte fantasma de Joaquim José da Silva Xavier, o Tiradentes, con su uniforme de alférez y la barba raspada, lo que revela Dios haberse dignado levantarlo de la sepultura en el apogeo de la esplendorosa juventud. Atrás, secundándolo con inagotable bravura, venía el cacique Araribóia, pintado para la lucha (2004: 141)

Ese relato inserta una galería de "grandes bustos históricos», como Deodoro da Fonseca, Mem de Sá, Getúlio Vargas, y hasta Gilberto Freyre y Gustavo Cor Corção, resucitados porque «Dios los hizo resurgir en vida». Como se sabe, esos últimos estaban vivos en la época y representaban, cada cual a su modo, el pensamiento conservador. Por otro lado, el fragmento atribuido al «famoso escritor» excluye (alegando tratarse de información «engańosa») la presencia de mujeres como Anita Garibaldi u Olga Benário.

7 «O líder do macabro Exército revoltoso não seria o Alferes Tiradentes, como garantia a obra de nosso defunto autor, mas sim um operário da indústria siderúrgica chamado Osman ou Osmar. Seu lugar-tenente não seria, da mesma forma, o fantasma hercúleo, porém impotente, do intrépido Araribóia [...]. Era tão-somente o oleiro negro Benedito Airão».

8 «A Grande Marcha seguia heroicamente pela Rio-Brasília, tendo à frente, como líder maior e incontestável, o esguio e solerte fantasma de Joaquim José da Silva Xavier, o Tiradentes, com seu uniforme de alferes e a barba raspada, o que revela Deus ter-se dignado erguê-lo da sepultura no apogeu da esplendorosa juventude. Atrás, secundando-o com inesgotável bravura, vinha o cacique Araribóia, pintado para a luta ». 
El primer narrador reafirma que la Rebelión de los Muertos no ocurrió de la forma como es narrado en el libro y, sorprendentemente, acusa de falsa también la versión del joven periodista, «notadamente en lo que se refería a la identidad de los integrantes del ejército revoltoso, aunque tentase revelar levemente las anónimas identidades de estos mismos integrantes, al punto de identificar como Osman, u Omar, un metalúrgico, el comandante de la infeliz columna» (2004: 144). Además de la caracterización de los participantes (¿gente sin brazos o personajes históricos?) el texto relativiza también la visibilidad de esos muertos que, después de tentativas infructíferas de comunicación con unos pocos operarios que consiguieron verlos, se disuelven en el aire.

Exponiendo los hechos y al mismo tiempo manteniéndolos en reiteradas oscilaciones, «A rebelião dos mortos» (La rebelión de los muertos) recrea, alegóricamente, episodios que eran frecuentes en la época, como las diferentes versiones oficiales, algunas inverosímiles, que el gobierno dictatorial inventaba. Recrea también el relato sobre las muertes inexplicables de individuos con voces disonantes, que eran callados por la censura o sumariamente eliminados como acontece al escritor y al periodista en el cuento.

Dublicado en Italia, con traducción de Antônio Tabucchi, en 1974 Zero fue lanzada
en el Brasil por la Codecri en 1975 y en julio del año siguiente recibió el premio de «Mejor ficción» de la Fundación Cultural del Distrito Federal. Pocos meses después de la premiación Zero fue censurado por el Ministerio de Justicia y prohibido en todo el territorio nacional. Volvió en circulación en 1979. La premiación en concurso literario, con la subsecuente visibilidad conquistada por la obra, tiene como resultado para los dos autores, Brandão e Emediato, la entrada de los censores en acción y la imposibilidad de divulgación de las obras premuadas — curiosamente, en ambos casos, por sectores de la cultura vinculados a la administración pública. No hay coincidencia en los episodios, hay la constatación de que la censura no intentaba cercenar la publicación de textos literarios, hasta por falta de infraestructura para hacer la lectura previa de todo lo que las editoras lanzaban. Se ejercía la censura a las narrativas literarias cuando estas se volvían blanco de denuncia, conforme se afirmó inicialmente.

En Protesto e o novo romance brasileiro (Protesta y el nuevo romance brasileño), Malcolm Silverman incluye Zero entre los romances de sátira política surrealista y afirma: 


\section{HELENA BONITO COUTO PEREIRA}

Zero es un descenso inexorable y poliforme a un infierno más tumultuoso que los romances del periodo [...]. Lenguaje bestial, diálogo crudo, sucesión ilógica [...] y la falta de cualquier estudio de personajes profundos - todo refuerza la locura sin esperanza de una sociedad deformada por el dominio de una policía arbitraria y un capitalismo sin disciplina [...]. Quebrando en pedazos la narrativa, Loyola consiguió traer al juego temático, no tanto la forma, sino la ausencia de forma, lo que prueba ser una dimensión adicional que otros romances políticos, tan fracturados como son, no consiguen igualar. (Silverman 2000: 362) ${ }^{9}$

El texto extenso e increíblemente deconstruido de Zero intercala algunos episodios verosímiles, así como grotescos (por ejemplo, el empleo del protagonista del matador de ratas en un cine decadente), a episodios marcados por la sátira surreal y por la brutalidad. Son numerosas las alusiones a censura, represión, arbitrariedad y violencia durante el gobierno militar:

El Escuadrón fue pidiendo los documentos que la Determinación 7.89796 exigía de cada uno: Identidad, Elector, Profesional, Buena Conducta, Antecedentes, Residencia, diplomas escolares, Salud (vacunas, fiebre amarilla, varicela, malaria, BCG), libreta de pago con las asociaciones religiosas [...], Seguro de Vida, Atestado de Contención Sexual.

José terminó trasladado paa la Delegación. Le faltaba un documento: el de la frecuencia escolar de los hijos.

-Pero no tengo hijos.

-Pero el señor es casado.

-Pero no tuve tiempo de tener hijos.

-Su mujer ha usado la píldora.

- Sí.

-Es prohibido (Brandáo 2001: 126) ${ }^{10}$

9 «Zero é uma descida inexorável e polimorfa a um inferno mais revoltante que o dos romances do período [...]. Linguagem bestialógica, diálogo cru, sucessão ilógica, [...] e a falta de qualquer estudo de personagem profundo - tudo reforça a loucura sem esperança de uma sociedade deformada pelo domínio de uma polícia arbitrária e um capitalismo sem disciplina [...]. Quebrando em pedaços a narrativa, Loyola consegue trazer ao jogo temático, não tanto a forma, mas a ausência de forma, o que prova ser uma dimensão adicional que outros romances políticos, tão fraturados como são, não conseguem igualar».

$10 \ll$ O Esquadrão foi pedindo os documentos que a Determinação 7.89796 exigia de cada um: Identidade, Eleitor, Profissional, Boa Conduta, Antecedentes, Residência, diplomas escolares, Saúde (vacinas febre amarela, 


\section{Incidente em Antares}

lestablecer la trayectoria literaria de Érico Veríssimo, con inicio en pleno regionalismo
y posterior direccionamiento para la crítica social y política, Flávio Loureiro Chaves afirma que su ficción

Se desdobla por diferentes etapas durante un periodo de cuarenta años, siempre manteniendo el cuestionario sobre la realidad social contemporánea. Digamos entonces que, con el pasar del tiempo, la propia naturaleza de los hechos históricos fue modificando la actitud del romancista delante de la realidad inmediata y lo forzó a revisar constantemente a las posiciones éticas a través de las cuales ordenó su mundo de ficción. (2001: 141) ${ }^{11}$

Ahora, habiendo escrito una vasta obra en que recrea literariamente la historia de su Estado natal, Veríssimo permaneció atento a la realidad social contemporánea y revisó constantemente sus propias posiciones éticas. Incidente em Antares también se apoya en la tradición gaúcha y presenta los procedimientos habituales del escritor que, en la primera parte del libro retrocede más de un siglo para relatar la formación del poblado que vendría a tornarse Antares. La trama central tiene por eje el retorno de siete muertes, que no habían sido enterrados porque los sepultureros se unieron a la huelga general decretada en 13 de diciembre de 1963, viernes.

Los siete muertos representaban variados segmentos sociales, que se rebelan, en ese extraño despertar, en una especie de orden jerárquica, que se inicia por la matriarca de una de las familias ricas de la ciudad y termina en la prostituta decaída, muerta por falta de asistencia adecuada en un hospital público. La secuencia incluye un abogado corrupto,

varíola, malária, BCG), caderneta de quitação com as associações religiosas (...), Seguro de Vida, Atestado de Contenção Sexual.

José terminou levado para a Delegacia. Faltava-lhe um documento: o da freqüência escolar dos filhos.

-Mas não tenho filhos.

-Mas o senhor é casado.

-Mas não deu tempo de ter filhos.

-Sua mulher tem usado a pílula.

- Tem.

- É proibido.»

11 «Se desdobra por diferentes etapas durante um período de quarenta anos, sempre mantendo a argüição sobre a realidade social contemporânea. Digamos então que, com o passar do tempo, a própria natureza dos fatos históricos foi modificando a atitude do romancista perante a realidade imediata e forçou-o a revisar constantemente as posições éticas através das quais ordenou seu mundo de ficção.» 
un pianista suicida, un zapatero anarquista y, antes de llegar a la cantina de la ciudad, asesinado por propra esposa, pasa por el joven que murió bajo tortura en la delegación. Tal composición de caracteres es suficiente para percibir claramente la intención alegórica de Veríssimo, que los coloca en el templete de la plaza, de donde hacen una especie de juicio final, denunciando la hipocresía y las irregularidades presentes en todas las esferas: en la administración pública, en la justicia, en la salud, en las relaciones familiares y sociales.

Después de la exposición irrestricta de las miserias el conflicto se resuelve, con el retorno de los muertos al cementerio. Para que todos los episodios del «lamentable incidente» sean olvidados, como si no hubiesen ocurrido, el perfecto desencadena la «operación caucho», la cual adhiere toda la población. Mientras tanto, como si fuese necesario, el narrador cierra el libro con la rutina ya restablecida, poco tiempo después, e interrumpida, eventualmente, por «bustos furtivos que en el silencio de la noche andan escribiendo en sus muros y paredes palabras y frases políticamente subversivas, cuando no pornográficas» (1985: 460). Un joven había sido abatido a tiros cuando escribía en un muro $y$, en las escenas finales, un hombre pasa por el lugar con su hijo:

-¿Qué es lo que está escrito allí, padre?

-Nada. Vamos andando, que ya estamos atrasados...

El pequeńo, mientras, para mostrar a los que estaban por allí que ya sabía leer, miró para la palabra pintada y comenzó a deletrearla en voz muy alta: «Li-ber...» - ¡Calla la boca, bobalicón! Exclamó el padre, casi en pánico. Y, empujando con fuerza la mano del hijo, lo llevó, casi a rastras, calle abajo (1985: 461) 12

A pesar de la contundencia de las denuncias y del carácter alegórico Incidente em Antares (Incidente en Antares), el romance pasó incólume por la censura. Verísimo se alinea al lado de escritores que, ya reconocidos, consiguen expresar repudio al régimen militar, sin ser molestados por un posicionamiento político que, expuesto alegóricamente, no llega a ser percibido como amenazador o subversivo.

12 «Que é que está escrito ali, pai?

-Nada. Vamos andando, que já estamos atrasados...

O pequeno, entretanto, para mostrar aos circunstantes que já sabia ler, olhou para a palavra de piche e começou a soletrá-la em voz muito alta: «Li-ber...»

-Cala a boca, bobalhão! Exclamou o pai, quase em pânico. E, puxando com força a mão do filho, levou-o, quase de arrasto, rua abaixo.» 


\section{Allegoría e ironía}

«La rebelión de los muertos», Zero e Incidente em Antares son narrativas que recurren a la alegoría, a la ironía y a otros procedimientos para llegar a la revelación de ansiedades propias de la intelectualidad brasileña en ese periodo. La cuestión puesta en los textos de ficción se sustenta en el deseo de expresar indignación, revuelta e inconformismo frente al poder arbitrario, a la supresión de libertades civiles y a la ausencia del estado de derecho.

Un estudio más minucioso ciertamente comprobará lo que se espera haber demostrado, a pesar de las limitaciones de este, en relación al alcance de la buena parta de las narrativas ficcionales alegóricas publicadas en los «años de plomo». En ellas se instauran realidades ficticias que se contraponen al conformismo y no se restringen, necesariamente, a los límites de un realismo estrecho o empobrecedor. El empleo creativo de un arsenal de recursos expresivos, entre ellos la alegoría y la ironía, permite a esos textos literarios alcanzar un nivel de elaboración artística suficiente para que, como literatura, puedan distinguirse del reportaje o del documento. Conforme apuntó la crítica especializada, alegoría y realismo no son fácilmente ajustables o combinables entre sí. Sin embargo, cuando la intención documental se subordina a la visión alegórica, nada impide que aflore la fruición estética. Censuradas o no, las narrativas de Emediato, Brandão y Veríssimo presentan cualidad textual que las mantienen en un lugar destacado en la producción literaria de esa difícil coyuntura recientemente superada, cuyos efectos se prolongan hasta el presente. 


\section{REFERENCIAS}

ArrigucCi JR., Davi

1999 Outros achados e perdidos. São Paulo: Companhia das Letras.

BARBIERI, Therezinha

2003 Ficção impura. Prosa brasileira dos anos 70, 80 e 90. Rio de Janeiro: Ed. UERJ.

Brandão, Ignacio de Loyola

2001 Zero. São Paulo: Global.

Chaves, Flávio Loureiro

2001 Érico Veríssimo - o escritor e seu tempo. Porto Alegre: Ed. da Universidade-UFRGS.

Emediato, Luiz Fernando

2004 «Rebelião dos mortos». En Trevas no paraíso. Histórias de amor e guerra nos anos de chumbo. São Paulo: Geração Editorial.

Franco, Renato

1998 Itinerário político do romance pós-64: A festa. São Paulo: Ed. da Unesp.

GASPARI, Elio

2003 A ditadura derrotada. São Paulo: Companhia das Letras.

aิ 2002a A ditadura envergonhada. São Paulo: Companhia das Letras.

क 2002 b A ditadura escancarada. São Paulo: Companhia das Letras.

Instituto Moreira SAlles

2001 "Cadernos de Literatura Brasileira». Ignacio de Loyola Brandão, N. o 11. Rio de Janeiro: Instituto Moreira Salles.

OTsuka, Edu Teruki

2001 Marcas da catástrofe. Experiência urbana e indústria cultural em Rubem Fonseca, João Gilberto Noll e Chico Buarque. São Paulo: Nankin. 
Pellegrini, Tânia

1999 A imagem e a letra. Aspectos da ficçáo brasileira contemporânea. Sáo Paulo: Mercado das Letras, Fapesp.

RufFato, Luiz

2004 «Por que ler Emediato hoje?». En Emediato, L. F. Trevas no paraíso. Histórias de amor e guerra nos anos de chumbo. São Paulo: Geração Editorial.

SCHWARZ, Roberto

1999 Sequências brasileiras. São Paulo: Companhia das Letras.

SiLVerman, Malcolm

2000 Protesto e o novo romance brasileiro. Rio de Janeiro: Civilização Brasileira.

SüSSEKIND, Flora

2004 Literatura e vida literária. Polêmicas, diários \& retratos. Belo Horizonte: Ed. UFMG.

VERÍSSIMO, Érico

1985 Incidente em Antares. Porto Alegre: Globo. 